\title{
The Glasgow Sustainable Urban Drainage System Management Project: Case Studies (Belvidere Hospital and Celtic FC Stadium Areas)
}

\author{
Miklas Scholz, ${ }^{*}$ Niall L. Corrigan, and Sara K. Yazdi \\ Institute for Infrastructure and Environment \\ School of Engineering and Electronics \\ College for Science and Engineering \\ The University of Edinburgh \\ Edinburgh, UK
}

\begin{abstract}
The Glasgow Sustainable Urban Drainage System (SUDS) Management Project satisfies the first phase of the Glasgow Surface Water Management Project. This is Glasgow City Council's contribution to the Transformation of Rural and Urban Spatial Structure (TRUST) project, one of the European Union's (EU) interregional (INTERREG IIIB) funded research projects. The remit of this EU project comprises also other representative regions in Europe. The project shows also how SUDS can contribute to the overall catchment dynamics of cities such as Glasgow, ultimately relieving stress on the current predominantly combined sewer system. Fifty-seven sites within 46 areas of Glasgow were identified for investigation. A detailed soil chemistry analysis, a preliminary SUDS feasibility assessment and a desk study relating to historical planning issues that may be relevant for subsequent future development and regeneration options were undertaken. Detailed design and management guidelines were then drafted for selected representative demonstration areas (Belvidere Hospital and Celtic FC Stadium Areas) of high public and property developers interest, and education value. A combination of infiltration trenches or swales with ponds or underground storage were the most likely SUDS options for the majority of the demonstration areas. Soil contamination issues were considered when selecting SUDS because heavy metals such as lead and zinc can cause environmental health problems.
\end{abstract}

Key words: Glasgow; sustainable urban drainage system; Brownfield; attenuation; pond; underground storage tank; soil contamination; heavy metal

*Corresponding author: Institute for Infrastructure and Environment, School of Engineering and Electronics, College for Science and Engineering, The University of Edinburgh, William Rankine Building, The King's Buildings, Mayfield Road, Edinburgh EH9 3JL, UK. Phone: +44 (0)131 650 6780; Fax: +44 (0)131650 6554; E-mail: m.scholz@ed.ac.uk. 


\section{INTRODUCTION}

\section{Water framework directive and SUDS}

$\mathbf{T}$ He European Union's (EU) Water Framework Directive (Council of European Communities, 2000), which came into force on 23 October 2000, requires all inland and coastal waters to reach "good status" by 2015. The Directive sets a framework that should provide substantial benefits for the long-term water quality management of waters. The implementation of sustainable urban drainage systems (SUDS) based on current guidelines (Jefferies et al., 1999; McKissok et al., 1999; CIRIA, 2000; Scholz, 2006) in Glasgow can help preventing flooding from watercourses and sewer systems, and combined sewer overflows to spill untreated sewage into receiving watercourses such as rivers and canals during storms (DEFRA, 2000; Scholz, 2004). Furthermore, SUDS can help to reduce the impact of diffuse pollution on urban watercourses by promoting passive treatment (D'Arcy and Frost, 2001). However, metals may leach out of the soil of SUDS embankments during winter, causing water quality problems (Scholz, 2004).

\section{Transformation of Rural and Urban Spatial Structure (TRUST) project applied in Glasgow}

In April 2000, the Commission of European Communities established a Community Initiative concerning trans-European cooperation, known as INTERREG IIIB. The INTERREG IIIB initiative relates to the whole of the European Union. One of the projects funded by this initiative is entitled Transformation of Rural and Urban Spatial Structure (TRUST). This project aims to develop new approaches to both spatial planning and land use to meet the challenges of continuing urbanization, along with reducing economic loss and reduction in biodiversity through the development of integral management methods.

The theme of TRUST is based upon multifunctional water storage, integral surface water management, and public and stakeholder participation. Six different authorities and institutions throughout Europe are currently contributing to this project. They are in alphabetical order: British Waterways (Watford, UK), Gewestelijke Ontwikkelingsmaatschappij (Brugge, Belgium), Glasgow City Council (Glasgow, UK), Hoogheemraadschap van Scieland (Rotterdam, The Netherlands), Provincie Noord Holland (Haarlam, The Netherlands), and University of Osnabrück (Osnabrück, Germany).

Glasgow City Council's contribution to the TRUST project is known as the "Glasgow Surface Water Management Project." The project proposes innovative urban drainage recommendations. The first study output is the
"The Glasgow Sustainable Urban Drainage System Management Project," led by Dr. Scholz and executed by the authors of this paper, and funded by The Royal Academy of Engineering and Glasgow City Council.

\section{Background to case studies}

The Belvidere Hospital site is located to the south of London Road (major road into Glasgow), and is owned by Kier Homes. It is in a prime development area due to its proximity to the Glasgow City centre and amenities such as parks, shopping centres, Celtic Park, and the proposed national indoor sports arena. The southern border of the site is adjacent to the River Clyde.

The Celtic FC Stadium area is located to the north of London Road (see above), $2 \mathrm{~km}$ from the City Center, in Glasgow's East End (also know as the Celtic Triangle). The area includes the Celtic FC Stadium (Celtic Park) to the east, visitor and coach car parking to the southwest, and housing (partly under construction) to the northeast. The west of the area is owned by Glasgow City Council.

\section{Rationale, aims, and objectives}

The feasibility to implement different SUDS throughout Glasgow and their potential contribution to the overall catchment dynamics has been studied. The data should help in understanding the challenges of holistic catchment management, diffuse pollution, and the "linking scales" in catchment management.

This project aims to come up with SUDS demonstration areas (case studies) that are representative for both different sustainable drainage techniques and different types of areas available for development and regeneration.

The objectives are to:

1. identify variables that determine the suitability of a site for the implementation of SUDS;

2. identify suitable SUDS sites within Glasgow;

3. classify qualitatively and quantitatively sites suitable for different SUDS technologies;

4. outline both a general SUDS decision support key and matrix;

5. identify representative SUDS technologies for representative sites that could be used for demonstration purposes;

6. provide detailed design and management guidelines, and a brief cost-benefit analysis for representative sites and representative SUDS techniques for information and education purposes; and

7. assess the soil contamination and the associated impact on environmental health. 


\section{METHODOLOGY AND EXPERIMENTAL PROTOCOLS}

\section{Glasgow}

Figure 1 is a map of Glasgow highlighting the spatial distribution of 46 areas (associated with 57 sites) that were identified as potentially suitable for the implementation of SUDS. Eight areas had the potential for more than one SUDS system, and were therefore subdivided into subareas (i.e., sites). Every effort has been made to investigate also areas currently represented only sparsely by discussing SUDS opportunities with planners employed by the Council.

\section{Site classification}

Fifty-seven sites were hierarchically classified (nine levels) according to their public acceptability, land costs, water supply, drainage issues, site dimensions, slope, groundwater table depth, fragmentation of ownership and ecological value (Fig. 2). The classification was based on expert water-engineering understanding, rather than on statistical evaluation, and account for flexibility in selecting (numerical) thresholds (e.g., estimated land cost). Moreover, this classification should be used as a general framework that supplements detailed frameworks and management guidelines dealing with specific regeneration issues such as leaching of metals (Kossen et al., 2002).
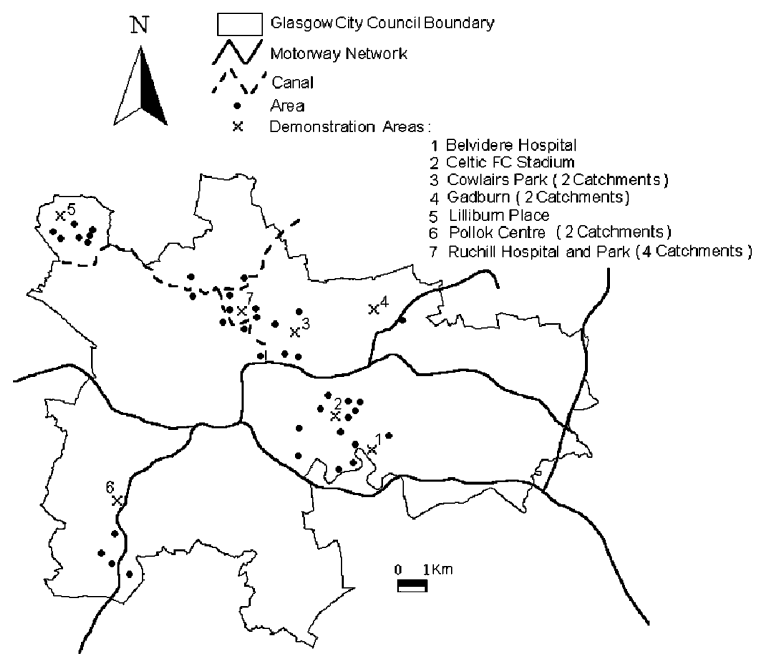

Figure 1. Indication of 46 potential areas comprising 57 sites for the implementation of sustainable urban drainage systems (SUDS). The SUDS demonstration areas have been highlighted.

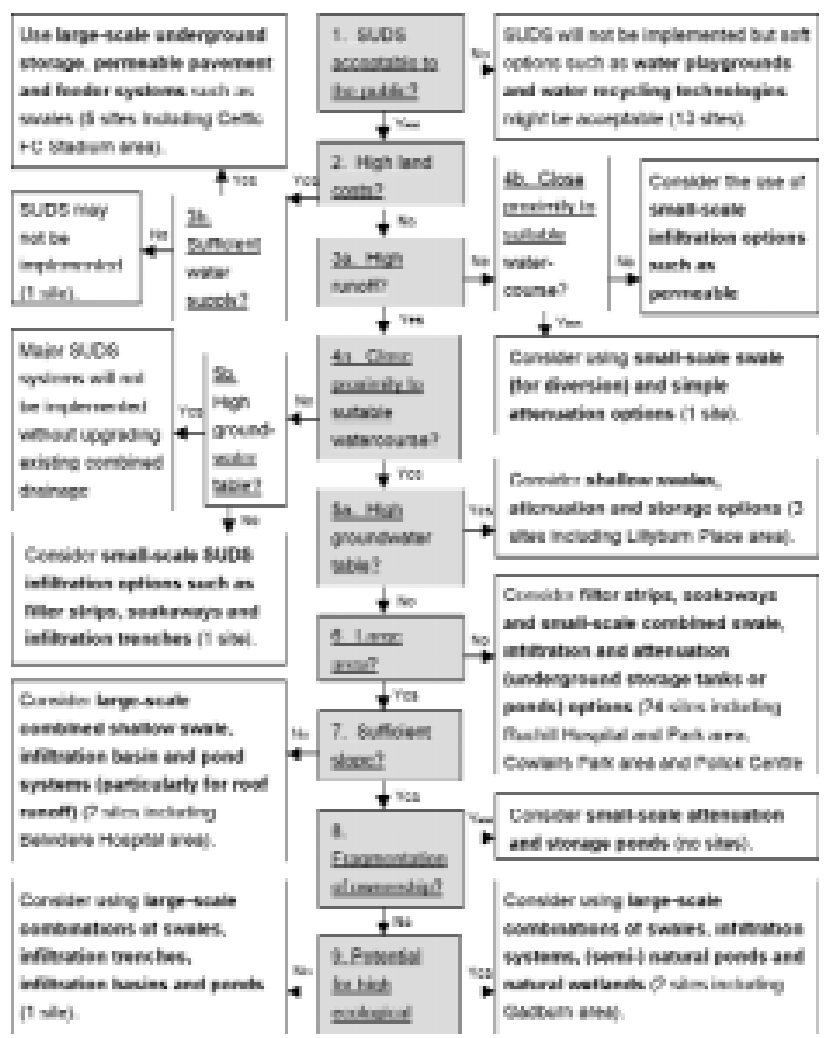

Figure 2. The sustainable urban drainage system (SUDS) decision support key and classification of 57 sites located in 46 areas available for regeneration and development.

\section{SUDS decision support key}

Sustainable urban drainage should not cause any public health problems, avoid pollution of the natural environment, minimize the use of resources, operate in the long term, and be adaptable to change in requirements (Butler and Parkinson, 1997). Taking this statement into consideration, the following list of criteria for defining SUDS options and a corresponding summary matrix (Table 1) have been proposed:

1. Runoff (low or high): the site has to be associated with a potential source of water (e.g., car park runoff) that results in sufficient runoff (to be defined on a case by case basis).

2. Catchment size (specified for individual SUDS options): the site needs to have sufficiently large dimensions (e.g., width $\geq 150 \mathrm{~m}$ and length $\geq 300 \mathrm{~m}$ ).

3. Area suitable for SUDS (specified for individual SUDS options): the site has to be acceptable for development, regeneration, or retrofitting to Glasgow City Council, developers, and the wider public (e.g., Greenfield and Brownfield areas). The site should 
Table 1. Sustainable urban drainage system (SUDS) decision support matrix.

\begin{tabular}{|c|c|c|c|c|c|c|c|c|c|c|}
\hline & Runoff & $\begin{array}{c}\text { Catch- } \\
\text { ment } \\
\text { size } \\
\left(m^{2}\right)\end{array}$ & $\begin{array}{c}\text { Area of } \\
\text { suitabi- } \\
\text { lity for } \\
\text { SUDS } \\
\text { feature }\end{array}$ & $\begin{array}{c}\text { Serious } \\
\text { contami- } \\
\text { nation }\end{array}$ & $\begin{array}{l}\text { Land } \\
\text { value }\end{array}$ & $\begin{array}{l}\text { Owner- } \\
\text { ship } \\
\text { frag- } \\
\text { mented }\end{array}$ & $\begin{array}{l}\text { High } \\
\text { ground- } \\
\text { water } \\
\text { level }\end{array}$ & $\begin{array}{l}\text { Suffi- } \\
\text { cient } \\
\text { channel } \\
\text { slope }\end{array}$ & $\begin{array}{l}\text { Potential } \\
\text { of high } \\
\text { ecological } \\
\text { impact }\end{array}$ & $\begin{array}{l}\text { Soil } \\
\text { infiltra- } \\
\text { tion }\end{array}$ \\
\hline Wetlands & High & $>50,000$ & $>5,000$ & No & $<2$ & No & N/A & N/A & Yes & N/A \\
\hline Ponds & High & $>15,000$ & $>50$ & No & $<3$ & Yes & N/A & N/A & N/A & N/A \\
\hline $\begin{array}{l}\text { Lined } \\
\text { ponds }\end{array}$ & High & $>15,000$ & $>50$ & Yes & $<3$ & Yes & N/A & N/A & N/A & N/A \\
\hline $\begin{array}{l}\text { Infiltration } \\
\text { basin }\end{array}$ & High & $>15,000$ & $>50$ & No & $<3$ & Yes & No & N/A & N/A & High \\
\hline Swale & High & N/A & $>200$ & No & $<3$ & No & No & Yes & N/A & N/A \\
\hline $\begin{array}{r}\text { Shallow } \\
\text { swale }\end{array}$ & High & N/A & $>200$ & No & $<3$ & No & Yes & Yes & N/A & N/A \\
\hline $\begin{array}{l}\text { Filter } \\
\text { strip }\end{array}$ & High & $>15,000$ & $>600$ & No & $<3$ & Yes & No & Yes & N/A & High \\
\hline $\begin{array}{l}\text { Soak- } \\
\text { away }\end{array}$ & Low & $>3,000$ & $>200$ & No & $<3$ & Yes & No & Yes & N/A & High \\
\hline $\begin{array}{l}\text { Infiltration } \\
\text { trench }\end{array}$ & Low & $>3,000$ & $>50$ & No & $<3$ & No & No & Yes & N/A & High \\
\hline $\begin{array}{l}\text { Permeable } \\
\text { pavement }\end{array}$ & $\begin{array}{l}\text { Low/ } \\
\text { High }\end{array}$ & N/A & N/A & No & N/A & Yes & N/A & N/A & N/A & High \\
\hline $\begin{array}{l}\text { Under- } \\
\text { ground } \\
\text { storage }\end{array}$ & $\begin{array}{l}\text { Low/ } \\
\text { High }\end{array}$ & N/A & $>40$ & Yes & N/A & Yes & N/A & N/A & N/A & N/A \\
\hline $\begin{array}{l}\text { Supplemen- } \\
\text { tary water } \\
\text { playground }\end{array}$ & Low & $>200$ & $>10$ & No & N/A & Yes & Yes & N/A & N/A & N/A \\
\hline
\end{tabular}

Land value: $1=\operatorname{low}\left(<£ 100 / \mathrm{m}^{2}\right), 2=\operatorname{medium}\left(\geq £ 100 / \mathrm{m}^{2}\right.$ and $\left.\leq £ 200 / \mathrm{m}^{2}\right), 3=$ high $\left(>£ 200 / \mathrm{m}^{2}\right) ; \mathrm{N} / \mathrm{A}=$ not applicable.

also be associated with a separate area to which water can drain (e.g., canal or river).

4. Serious soil contamination (yes or no): the site should not be associated with major soil contamination issues.

5. Land value (low, medium, high, or not applicable): the land costs should preferably be not too high (e.g., $<£ 200 / \mathrm{m}^{2}$ ) before development or regeneration work has commenced.

6. Fragmentation of ownership (yes or no): the site should preferably be owned by only a few individuals or organisations (e.g., $<5$ parties).

7. High groundwater level (yes, no or not applicable): the site should preferably be associated with a low groundwater table (e.g., groundwater level $>2 \mathrm{~m}$ below ground level).

8. Sufficient channel slope (yes, no or not applicable): the site should have a sufficient slope (e.g., $\geq 1$ in $50 \mathrm{~m}$ ) to enable conveyance structures to function properly. However, the site should not be too steep to make three-dimensional SUDS features too expensive.
9. Potential of high ecological impact (yes, no or not applicable): the site should be of potentially high ecological impact in the future, but not during the planning phase (e.g., not a scientific interest [SSSI]).

10. Soil infiltration (low, high, or not applicable). The site should have sufficiently high soil infiltration, if filtration is considered to be desirable for the proposed SUDS structure.

The representative SUDS demonstration areas have been selected based on these criteria (see above and Table 1). Only seven areas suitable for SUDS implementation are not represented by the selected demonstration areas (Fig. 2). However, it has to be emphasized that the selection is rather qualitative than quantitative considering that most selection criteria do not require a numerical assessment. It follows that the SUDS classification is similar to an expert system, and not to a statistically unbiased assessment that would not be suitable in this case anyway because of the lack of numerical information such as land value (e.g., recognizing also the future potential after regeneration).

ENVIRON ENG SCI, VOL. 23, NO. 6, 2006 


\section{Fieldwork activities}

Soil was sampled twice: selected samples were initially taken at a few locations where major SUDS structures were likely to be implemented. Composite samples were taken at $10 \mathrm{~cm}$ depth intervals within trenches of up to approximately $55 \mathrm{~cm}$ depth.

Further samples were taken at locations that are part of a proposed wider SUDS structure and that were located most closely to the nearest node of a randomly placed $50 \times 50 \mathrm{~m}$ equally spaced sampling grid. Only one sample at $50 \mathrm{~cm}$ depth per sampling site was taken during a second expedition.

If a sampling location was not acceptable (e.g., below tarmac or a house), an alternative representative sampling location was determined up to $5 \mathrm{~m}$ (if not stated otherwise below) away from the original location. However, if no sampling locations deemed to be appropriate, the location was not sampled and a "not accessible" entry was located on the map showing the sampling strategy and locations.

\section{Analytical work}

The soil recording and pretreatment before analysis was carried out in agreement with British Standards (British Standard Institute, 1999a, 2002). The determination of particle size distribution was also carried out according to British Standards (British Standard Institute, 1999b).

Composite samples were collected and stored at $-10^{\circ} \mathrm{C}$ prior to analysis. After thawing, approximately $2.5 \mathrm{~g}$ of each soil sample was weighed into a $100-\mathrm{mL}$ digestion flask to which $21 \mathrm{~mL}$ of hydrochloric acid (strength of $37 \%, \mathrm{v} / \mathrm{v}$ ) and $7 \mathrm{~mL}$ of nitric acid (strength of $69 \%, \mathrm{v} / \mathrm{v}$ ) were added. The mixtures were then heated on a Kjeldahl digestion apparatus (Fisons, UK) for at least $2 \mathrm{~h}$. After cooling, all solutions were filtered through a Whatman Number 541 hardened ashless filter paper into 100 -mL volumetric flasks. After rinsing the filter papers, solutions were made up to the mark with deionized water. The method was adapted from the section "Nitric Acid-Hydrochloric Acid Digestion" (American Public Health Association, 1995).

An Inductively Coupled Plasma Optical Emission Spectrometer (ICP-OES) was used for the analysis of metals and other heavy elements. Total concentrations of elements in filtered (Whatman 1.2- $\mu \mathrm{m}$ cellulose nitrate membrane filter) samples were determined by ICP-OES using a TJA IRIS instrument (ThermoElemental, USA). Multi-element calibration standards with a wide range of concentrations were used and the emission intensity measured at appropriate wavelengths.

Concerning the analysis of major nutrients, $2 \mathrm{~mL}$ sulphuric acid (strength of $98 \%, \mathrm{v} / \mathrm{v}$ ) and $1.5 \mathrm{~mL}$ hydrogen peroxide (strength of 30\%, v/v) were used as an extraction media (Allen, 1974). Approximately $0.1 \mathrm{~g}$ of each dried sample and the associated digestion media were placed in a tube and heated at $320^{\circ} \mathrm{C}$ for $6 \mathrm{~h}$. Aliquots were taken and digests were made up to $100 \mathrm{~mL}$ with distilled water.

For analysis of total nitrogen (Ntotal), the following procedure was adopted: Ammonium (present in the digest) reacts with hypochlorite ions generated by alkaline hydrolysis of sodium dichloroisocyanurate. The reaction forms monochloroamine, which reacts with salicylate ions in the presence of sodium nitroprusside to form a blue indephenol complex. This complex is measured colorimetrically at $660 \mathrm{~nm}$ using a Bran \& Luebbe (Northampton, UK) autoanalyzer (model AAIII).

For analysis of total phosphorus (Ptotal), the following procedure was adopted: Ortho-phosphate (present in the digest) reacts with ammonium molybdate in the presence of sulphuric acid to form a phosphomolybdenum complex. Potassium antimonyl tartrate and ascorbic acid are used to reduce the complex, forming a blue color, which is proportional to the Ptotal concentration. Absorption was measured at $660 \mathrm{~nm}$ using a Bran \& Luebbe autoanalyzer (model AAIII).

For the analysis of total potassium (Ktotal), the digest was analyzed by a flame atomic absorption spectrometer (Unicam 919, Cambridge, UK) at a wavelength of 766.5 $\mathrm{nm}$ and with a bandpass of $1.5 \mathrm{~nm}$. Standards were prepared in 100-mL flasks using $2 \mathrm{~mL}$ concentrated sulphuric acid and $1.5 \mathrm{~mL}$ hydrogen peroxide (30\% v/v) and made up to mark with deionized water. Caesium at a concentration of $100 \mathrm{mg} / \mathrm{L}$ was added to both standards and digests to overcome ionisation.

Subsamples of $3 \pm 0.1 \mathrm{~g}$ of field moist soil were mixed with an excess of sodium sulphate (Analytical Grade,

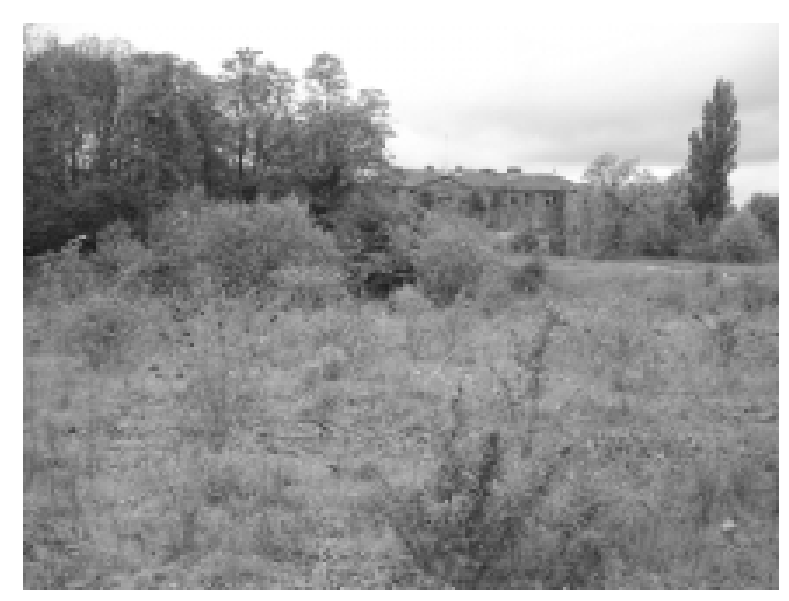

Figure 3. Belvidere Hospital area: site photograph taken on 14 May 2004. 
Fisher, UK) to make it "free flowing" and the resulting mixture extracted in $10 \mathrm{~mL}$ of HPLC grade dichloromethane (Fisher, UK) in an ultrasonic bath (Model XB14, Grant instruments, Cambridge, UK) for $10 \mathrm{~min}$. After agitation, samples were filtered through $0.45 \mu \mathrm{m}$ nylon syringe filters $\left(\mathrm{Qm}_{\mathrm{X}}\right.$ Laboratories Limited, Thaxted, UK).

The sample extracts were scanned for the presence of organic contaminants by HP 6980 gas chromatograph coupled to HP 6973 mass spectrometer. A $4 \mu \mathrm{L}$ aliquot of each sample was injected in the splitless mode onto a $30 \mathrm{~m}$ HP5MS fused silica column directly coupled to the ion source of an HP 6973 mass spectrometer.

The mass spectrometer was run in the scanning mode with a mass range of 50 to 700 . Identification of the peaks on the total ion chromatograms was made using libraries of preinstalled databases of reference spectra. An initial peak width and initial threshold values were set to identify significant peaks.

\section{Data analysis and software used}

The data analysis was carried out using Microsoft Excel, and statistical methods outlined elsewhere (Fowler and Cohen, 1998) were applied. ArcView was used to draw design proposals.

\section{Belvidere Hospital area case study}

The Belvidere (not Belvedere as usually read) Hospital area is located approximately Longitude $4^{\circ} 12^{\prime}$ West and Latitude $55^{\circ} 51^{\prime}$ north. The area has been cleared of all surface structures for new housing, with one remaining former hospital building, which is a Grade B Listed Building. However, parts of the area contain residual housing foundations below the current ground level. Nev-

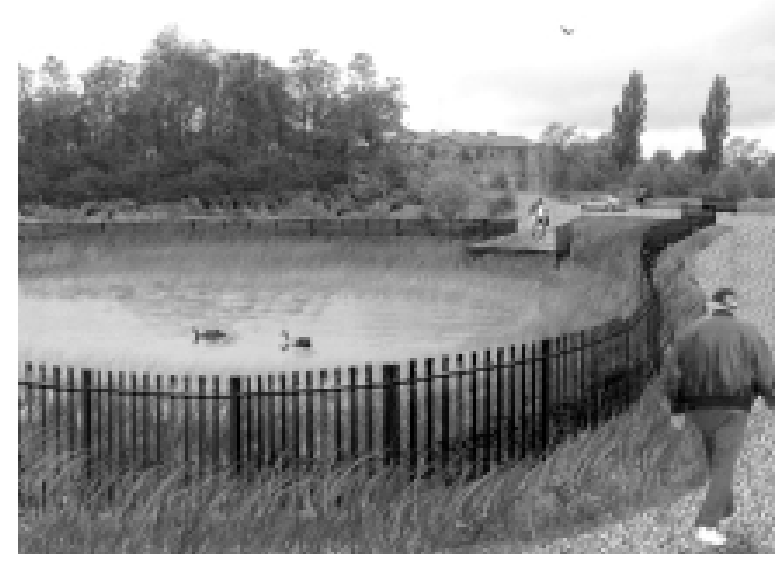

Figure 4. Belvidere Hospital area: artist impressions of proposed site development (computer animation).

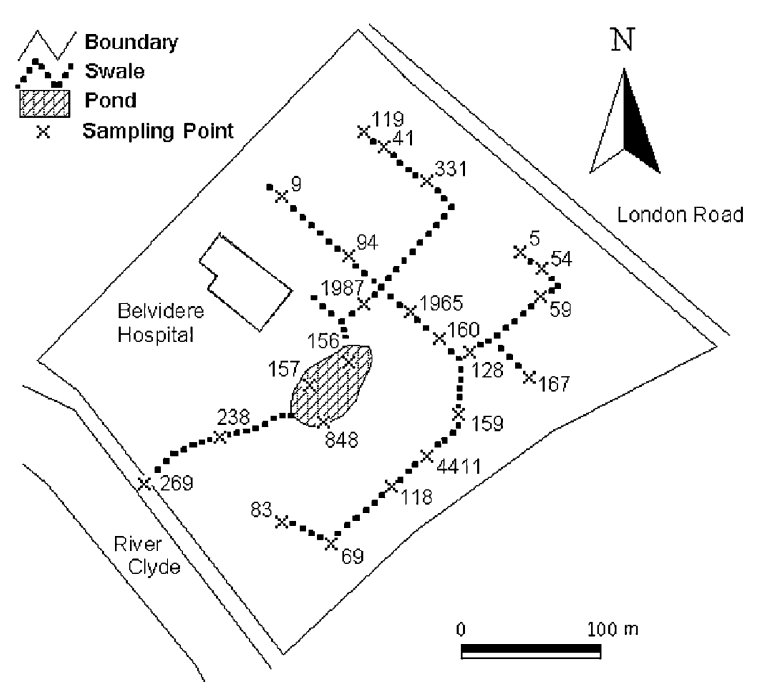

Figure 5. Belvidere Hospital area: spatial distribution of lead (mg/kg dry weight) at $50 \mathrm{~cm}$ depth on 5 July 2004.

ertheless, the overall topography of the site is even. Future development of this site for housing will require the removal of all residual foundations and asphalted areas (Figs. 3-6).

The main entrance driveway of the original hospital still exists with two large semivegetated areas (mainly rows of tall trees) flanking both sides. The remaining building on the area is situated to the west. To the south of the building is a steep embankment covered in dense woodland. The slope increases approximately from east to west, and is at its maximum $60^{\circ}$. At the base of this embankment (not within the area boundary marked by a $3 \mathrm{~m}$ high corrugated iron fence), runs a public walk and cycle path along the River Clyde. The height difference from the crest of the embankment down to the walkway is approximately $11 \mathrm{~m}$. However, this area is likely to remain unaffected by any building and road construction works due to its potentially high ecological and amenity value.

A desk study concerning the Belvidere Hospital proved to be unrewarding, as there were no historical documents held by Glasgow City Council pertaining to this area. However, the area is known to have been a hospital for approximately 100 years, and during this time the hospital grounds were subjected to the cleaning of hospital equipment, and might be contaminated with diffuse hospital waste.

\section{Celtic FC Stadium area case study}

The Celtic FC Stadium Area is approximately bordered by Janefield Street in the northeast, Stamford Street in the northwest, Dalriada Street in the southeast, and Lon- 


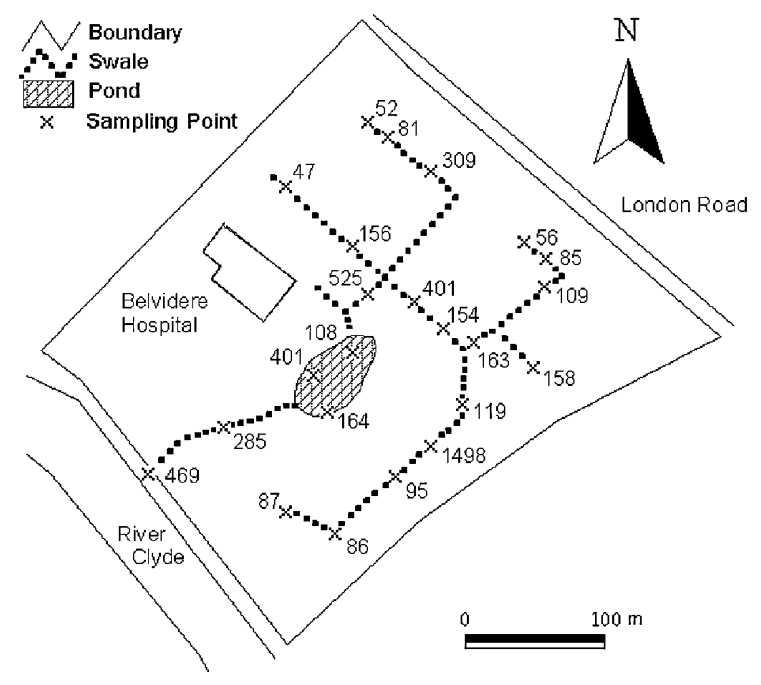

Figure 6. Belvidere Hospital area: spatial distribution of zinc (mg/kg dry weight) at $50 \mathrm{~cm}$ depth on 5 July 2004.

don Road in the south. A major part of the area in the west is used as a car park. The Celtic stadium is located in the southeast of the demonstration area.

The immediate Celtic FC Stadium Area is located approximately Longitude $4^{\circ} 13^{\prime}$ west and Latitude $55^{\circ} 51^{\prime}$ north. The Celtic Park stadium has capacity for approximately 60,000 spectators, and occupies a prime location in the heart of Glasgow's East End. On home match days, the stadium is generally filled to capacity (approximately 26 times per year between July and May), and this volume of visitors to the area clearly impacts on any integrated SUDS in the future.

Previous site investigations in this area show that the site is underlain by sandstones, siltstones, and mudstones, with seams of coal belonging to the Lower and Middle Coal Measures of the Carboniferous System. The natural superficial deposits are indicated on glacial maps to be alluvial clay and silt, partly overlain by made ground. The total thickness of superficial deposits is indicated to be between 20 and $30 \mathrm{~m}$.

The 1980 investigation of the areas as recorded in the Glasgow City Council's Geodatabank showed the general succession to be made ground with a thickness between 1.7 and $10.8 \mathrm{~m}$ and clay with sand bands with a thickness of at least $2 \mathrm{~m}$ (Glasgow City Council, 1995). The granular constituents of the made ground are in a generally medium dense state of compaction, but the cohesive constituents are generally in a soft or very soft state (Glasgow City Council, 1980).

The groundwater level in this area is at a depth between 7 and $8 \mathrm{~m}$, based on borehole data. Seepage of wa- ter was recorded in a couple of boreholes, but the report indicates that groundwater did not gather during the time of boring in the remaining boreholes. However, it is possible that pockets of perched groundwater may occur anywhere in made ground (Glasgow City Council, 1980).

The northern parts of the site, the areas located between Janefield Street and Stamford Street, are currently under redevelopment. There is a coach parking located in the East of the area that is expected to be retained. There are a number of occupied and unoccupied low standard housing blocks in the West. An older housing estate will be demolished, and the site will subsequently be redeveloped.

The East End regeneration route will be located to the west of the demonstration area. It follows that large underground storage facilities would be required to attenuate highway runoff in the future.

\section{RESULTS}

\section{SUDS and soil quality}

Figure 2 shows the outline of the SUDS decision support key and the classification of all sites visited during the exploratory stage of this project. The key may be used in combination with Table 1 outlining a SUDS decision support matrix. This matrix has been tested with the exploratory data set collected during the site visits, and Table 2 summarizes the outcome of the application of this tool. The findings for SUDS structures in Table 2 are based on the assumption that the soil contamination issues for all sites have been identified during the planning phase, and that contaminated soil will be removed wherever relevant soil contamination guidelines and/or the introduction of unlined SUDS structures require such a measure.

Concerning nutrients and heavy metals, Table 3 summarizes the soil quality for the most important nutrients and metals at $10 \mathrm{~cm}$ depth within Glasgow. Table 3 allows the reader to compare the contamination for selected demonstration sites with the mean contamination for the whole of Glasgow. Moreover, Table 4 shows the major nutrients and heavy metals at different soil depths during the exploratory investigation. The individual contamination profiles can be compared with the average contamination profiles for Glasgow (Table 4).

Table 5 shows major nutrients and selected heavy metals for soil at a depth of $50 \mathrm{~cm}$ for all areas that would be occupied by SUDS structures. Contamination level variations at a depth relevant for conveyance structures such as swales are shown to give the reader an indication of the potential remediation work to be undertaken 
Table 2. Sustainable urban drainage system (SUDS) options based on the SUDS decision support matrix (Table 1).

\begin{tabular}{|c|c|c|c|c|c|c|c|c|c|c|c|}
\hline Area & $\begin{array}{c}\text { Catch- } \\
\text { ment }\end{array}$ & $\begin{array}{l}\text { Wet- } \\
\text { land }\end{array}$ & Pond & $\begin{array}{c}\text { Infiltra- } \\
\text { tion } \\
\text { basin }\end{array}$ & Swale & $\begin{array}{c}\text { Infiltra- } \\
\text { tion } \\
\text { trench }\end{array}$ & $\begin{array}{l}\text { Soak- } \\
\text { away }\end{array}$ & $\begin{array}{l}\text { Filter } \\
\text { strip }\end{array}$ & $\begin{array}{c}\text { Perme- } \\
\text { able } \\
\text { pave- } \\
\text { ment }\end{array}$ & $\begin{array}{l}\text { Under- } \\
\text { ground } \\
\text { storage }\end{array}$ & $\begin{array}{l}\text { Water } \\
\text { play- } \\
\text { ground }\end{array}$ \\
\hline $\begin{array}{l}\text { Belvidere } \\
\text { Hospital }\end{array}$ & $\begin{array}{l}\text { Entire } \\
\text { area }\end{array}$ & & XXX & $\mathrm{X}$ & $\mathrm{XX}$ & $\mathrm{X}$ & & & XX & $\mathrm{X}$ & XX \\
\hline $\begin{array}{l}\text { Celtic FC } \\
\text { Stadium }\end{array}$ & $\begin{array}{l}\text { Entire } \\
\text { area }\end{array}$ & & & & & $\mathrm{X}$ & $\mathrm{X}$ & & XX & XXX & \\
\hline Cowlairs & North & & XXX & X & XX & X & X & X & XX & X & XX \\
\hline Park & South & & XXX & & XX & & $\mathrm{X}$ & XX & XX & $\mathrm{X}$ & XX \\
\hline \multirow[t]{2}{*}{ Gadburn } & North & $\mathrm{X}$ & XXX & & XX & $\mathrm{X}$ & & & XX & $\mathrm{X}$ & XX \\
\hline & South & XXX & XX & & XX & & & & XX & X & XX \\
\hline $\begin{array}{c}\text { Lillyburn } \\
\text { Place }\end{array}$ & $\begin{array}{l}\text { Entire } \\
\text { area }\end{array}$ & & $\mathrm{X}$ & & & XXX & $\mathrm{X}$ & & X & & $\mathrm{X}$ \\
\hline \multirow{6}{*}{$\begin{array}{l}\text { Pollok } \\
\text { Centre } \\
\text { Ruchill } \\
\text { Hospital } \\
\text { and } \\
\text { Park }\end{array}$} & West & & & & XX & $\mathrm{X}$ & & & XX & XXX & \\
\hline & East & & X & & XXX & XX & $\mathrm{X}$ & & XX & $\mathrm{X}$ & $\mathrm{X}$ \\
\hline & $\begin{array}{r}\text { North- } \\
\text { east }\end{array}$ & & & & XX & & & & $X X$ & XXX & \\
\hline & $\begin{array}{r}\text { South- } \\
\text { east }\end{array}$ & & & & XX & & & & XX & XXX & \\
\hline & South & & XXX & & XX & & & & XX & X & XX \\
\hline & West & & XXX & & XX & X & X & X & XX & X & XX \\
\hline
\end{tabular}

$\mathrm{X}=$ possible option; $\mathrm{XX}=$ recommended option; $\mathrm{XXX}=$ predominant SUDS design feature.

for unlined SUDS structures to avoid leaching out of nutrients and metals from the soil into the runoff (Table 5).

Concerning organic contaminants, Fig. 7 shows an example gas chromatograph result for a representative demonstration area (Belvidere Hospital). The largest peak observed was an artefact of the extraction procedure, and showed up in the method blank as well as all the samples.

Table 3. Major total nutrients and major heavy metals ( $\mathrm{mg} / \mathrm{kg}$ dry weight): comparison of soil quality at $10 \mathrm{~cm}$ depth during the exploratory investigation of 57 sites.

\begin{tabular}{|c|c|c|c|c|c|c|c|c|c|c|c|c|}
\hline Area & Site & $N$ & $P$ & $K$ & $A l$ & $\mathrm{Cr}$ & $\mathrm{Cu}$ & $R e$ & $M n$ & $N i$ & $P b$ & $Z n$ \\
\hline \multirow{2}{*}{$\begin{array}{c}\text { Belvidere } \\
\text { Hospita }\end{array}$} & North & 1,951 & 771 & 7,601 & 13,173 & 56 & 8 & 18,100 & 1,169 & 23 & 478 & 147 \\
\hline & South & 351 & 391 & 5,492 & 6,688 & 94 & 10 & 29,724 & 301 & 17 & 35 & 52 \\
\hline \multirow{2}{*}{$\begin{array}{l}\text { Celtic FC } \\
\text { stadium }\end{array}$} & North & 1,991 & 815 & 2,290 & 7,874 & 78 & 30 & 30,783 & 528 & 12 & 103 & 135 \\
\hline & East & 724 & 615 & 3,496 & 10,695 & 112 & 88 & 29,566 & 570 & 444 & 346 & 370 \\
\hline $\begin{array}{c}\text { Cowlairs } \\
\text { Park }\end{array}$ & North & 1,476 & 384 & 3,817 & 4,033 & 908 & 47 & 19,053 & 526 & 29 & 59 & 92 \\
\hline \multirow{2}{*}{$\begin{array}{c}\text { Park } \\
\text { Gadburn }\end{array}$} & South & 625 & 841 & 8,963 & 15,998 & 23 & 10 & 35,441 & 476 & 33 & 46 & 71 \\
\hline & South & 2,283 & 554 & 3,522 & 9,330 & 74 & 31 & 21,312 & 339 & 27 & 85 & 85 \\
\hline \multicolumn{2}{|l|}{$\begin{array}{c}\text { Lillyburn } \\
\text { Place }\end{array}$} & 124 & 213 & 1,607 & 4,839 & 66 & 14 & 24,883 & 374 & 19 & 51 & 45 \\
\hline \multicolumn{2}{|l|}{$\begin{array}{l}\text { Pollok } \\
\text { Centre }\end{array}$} & 524 & 290 & 9,260 & 13,156 & 147 & 72 & 28,847 & 548 & 114 & 145 & 121 \\
\hline \multirow{6}{*}{$\begin{array}{l}\text { Ruchill } \\
\text { Hospital } \\
\text { and } \\
\text { Park }\end{array}$} & Northeast & 1,840 & 568 & 7,813 & 3,125 & 13 & 30 & 22,065 & 416 & 27 & 170 & 123 \\
\hline & East & 554 & 280 & 3,243 & 2,765 & 7 & 22 & 15,809 & 483 & 17 & 374 & 217 \\
\hline & Centre-east & 2,308 & 467 & 3,393 & 3,653 & 15 & 41 & 21,629 & 283 & 23 & 451 & 231 \\
\hline & South & 505 & 308 & 4,315 & 9,131 & 77 & 34 & 24,688 & 594 & 25 & 1307 & 434 \\
\hline & Northwest & 2,412 & 716 & 3,884 & 11,507 & 78 & 37 & 23,606 & 311 & 30 & 194 & 158 \\
\hline & Park & 1,663 & 575 & 7,025 & 4,515 & 21 & 33 & 33,096 & 504 & 35 & 298 & 135 \\
\hline \multicolumn{2}{|c|}{ All sites for all areas } & 1,612 & 605 & 4,562 & 12,538 & 96 & 72 & 27,375 & 485 & 34 & 198 & 180 \\
\hline
\end{tabular}


Table 4. Major total nutrients and major heavy metals ( $\mathrm{mg} / \mathrm{kg}$ dry weight): comparison of soil quality at different depths during the exploratory investigation.

\begin{tabular}{|c|c|c|c|c|c|c|c|c|c|c|}
\hline \multirow[b]{2}{*}{ Area } & \multirow{2}{*}{$\begin{array}{l}\text { Depth } \\
(\mathrm{cm})\end{array}$} & \multirow[b]{2}{*}{ Count } & \multicolumn{2}{|c|}{$N$} & \multicolumn{2}{|c|}{$P$} & \multicolumn{2}{|c|}{$P b$} & \multicolumn{2}{|c|}{$Z n$} \\
\hline & & & Mean & $S D$ & Mean & $S D$ & Mean & $S D$ & Mean & $S D$ \\
\hline Belvidere & 10 & 2 & 731 & 813.7 & 423 & 241.5 & 145 & 222.4 & 69 & 53.2 \\
\hline \multirow[t]{4}{*}{ Hospital } & 20 & 2 & 801 & 781.7 & 397 & 251.5 & 157 & 215.7 & 80 & 53.1 \\
\hline & 30 & 2 & 933 & 716.4 & 450 & 248.2 & 222 & 200.8 & 110 & 60.4 \\
\hline & 40 & 1 & 418 & - & 402 & - & 117 & - & 57 & - \\
\hline & 50 & 1 & 453 & - & 316 & - & 78 & - & 77 & - \\
\hline \multirow{3}{*}{$\begin{array}{r}\text { Celtic FC } \\
\text { stadium }\end{array}$} & 10 & 2 & 1,357 & 896.2 & 715 & 141.3 & 225 & 171.8 & 253 & 166.3 \\
\hline & 20 & 2 & 1,160 & 626.5 & 666 & 299.6 & 239 & 28.3 & 281 & 20.2 \\
\hline & 30 & 2 & 1,373 & 471.3 & 1072 & 188.3 & 809 & 157.3 & 692 & 158.9 \\
\hline Cowlairs & 10 & 2 & 1,102 & 412.2 & 653 & 301.5 & 55 & 15.4 & 82 & 11.8 \\
\hline \multirow[t]{2}{*}{ Park } & 20 & 2 & 1,779 & $1,066.8$ & 621 & 281.1 & 89 & 63.5 & 104 & 36.5 \\
\hline & 30 & 2 & 1,786 & $1,058.8$ & 459 & 174.1 & 106 & 67.6 & 120 & 44.1 \\
\hline \multirow[t]{5}{*}{ Gadburn } & 10 & 1 & 2,283 & - & 554 & - & 85 & - & 85 & - \\
\hline & 20 & 1 & 9,937 & - & 919 & - & 236 & - & 141 & - \\
\hline & 30 & 1 & 5,156 & - & 944 & - & 187 & - & 86 & - \\
\hline & 40 & 1 & 5,916 & - & 1101 & - & 181 & - & 121 & - \\
\hline & 50 & 1 & 3,740 & - & 1026 & - & 369 & - & 437 & - \\
\hline Lillyburn & 10 & 1 & 124 & - & 213 & - & 51 & - & 45 & - \\
\hline \multirow[t]{3}{*}{ Place } & 20 & 1 & 156 & - & 581 & - & 41 & - & 97 & - \\
\hline & 30 & 1 & 219 & - & 629 & - & 55 & - & 90 & - \\
\hline & 40 & 1 & 213 & - & 761 & - & 85 & - & 91 & - \\
\hline Pollok & 10 & 1 & 534 & - & 290 & - & 145 & - & 121 & - \\
\hline \multirow[t]{3}{*}{ Centre } & 20 & 1 & 688 & - & 262 & - & 153 & - & 91 & - \\
\hline & 30 & 1 & 381 & - & 178 & - & 14 & - & 95 & - \\
\hline & 40 & 1 & 336 & - & 254 & - & 145 & - & 91 & - \\
\hline Ruchill & 10 & 6 & 1,547 & 836.3 & 486 & 168.4 & 466 & 425.5 & 216 & 115.2 \\
\hline Hospital & 20 & 6 & 1,330 & $1,559.6$ & 505 & 400.0 & 194 & 126.8 & 155 & 98.0 \\
\hline And & 30 & 6 & 1,372 & $1,387.6$ & 480 & 279.1 & 294 & 252.8 & 194 & 132.7 \\
\hline \multirow[t]{2}{*}{ Park } & 40 & 3 & 1,146 & 444.0 & 309 & 58.5 & 105 & 47.7 & 51 & 5.3 \\
\hline & 50 & 3 & 1,062 & 611.3 & 301 & 46.3 & 128 & 27.6 & 64 & 14.5 \\
\hline \multirow{5}{*}{$\begin{array}{l}\text { All sites for } \\
\text { all areas }\end{array}$} & 10 & 40 & 1,612 & $1,164.4$ & 605 & 255.9 & 198 & 218.4 & 180 & 157.1 \\
\hline & 20 & 41 & 1,583 & $1,721.2$ & 529 & 240.4 & 191 & 192.0 & 181 & 137.0 \\
\hline & 30 & 36 & 1,444 & $1,376.8$ & 510 & 249.2 & 192 & 243.4 & 165 & 152.0 \\
\hline & 40 & 21 & 1,802 & $1,793.9$ & 588 & 291.8 & 138 & 109.9 & 156 & 161.0 \\
\hline & 50 & 17 & 2,227 & $3,157.8$ & 617 & 428.8 & 203 & 179.2 & 186 & 220.3 \\
\hline
\end{tabular}

SD, standard deviation.

\section{Case studies}

A planimeter investigation has shown that the horizontal area of the Belvidere Hospital area available for the integration of SUDS techniques would be $94,000 \mathrm{~m}^{2}$ (Figs. 5 and 6).

Figure 3 shows a photograph of the site for which a major SUDS feature is planned. In comparison, Fig. 4 shows an artist impression of this site after regeneration. The proposed SUDS design for the
Belvidere Hospital area is shown in Figs. 5 and 6. Figure 7 shows an example of a total ion chromatogram.

Figure 8 shows a photograph of the site for which a major SUDS feature is planned. The proposed SUDS design for the Celtic FC Stadium area is shown in Figs. 9 and 10. A planimeter investigation has shown that the horizontal area of the Celtic FC Stadium area (excluding Celtic Park) available for the integration of SUDS techniques would be $58,500 \mathrm{~m}^{2}$. 
Table 5. Major total nutrients and major heavy metals $(\mathrm{mg} / \mathrm{kg}$ dry weight): comparison of soil quality at a depth of $50 \mathrm{~cm}$ for all areas that would be occupied by SUDS structures.

\begin{tabular}{|c|c|c|c|c|c|c|c|c|c|}
\hline \multirow[b]{2}{*}{ Area } & \multirow[b]{2}{*}{ Count } & \multicolumn{2}{|c|}{$N$} & \multicolumn{2}{|c|}{$P$} & \multicolumn{2}{|c|}{$P b$} & \multicolumn{2}{|c|}{$Z n$} \\
\hline & & Mean & $S D$ & Mean & $S D$ & Mean & $S D$ & Mean & $S D$ \\
\hline Belvidere Hospital & 23 & 816 & 331.1 & 532 & 220.1 & 505 & $1,012.4$ & 244 & 307.6 \\
\hline Celtic FC stadium & 8 & 1,572 & 343.7 & 665 & 154.5 & 651 & 651.1 & 439 & 168.9 \\
\hline Cowlairs Park & 31 & 733 & 348.9 & 453 & 234.4 & 107 & 57.4 & 98 & 57.8 \\
\hline Gadburn & 22 & 2,458 & $2,748.0$ & 596 & 339.5 & 124 & 114.1 & 146 & 119.0 \\
\hline Lillyburn Place & 8 & 708 & 320.4 & 604 & 189.8 & 96 & 35.0 & 90 & 31.5 \\
\hline Ruchill Hospital and Park & 33 & 815 & 364.2 & 500 & 721.8 & 262 & 252.7 & 138 & 119.5 \\
\hline
\end{tabular}

$\mathrm{SD}=$ standard deviation; sampling sites have been chosen based on proximity to nodes on a $50 \times 50 \mathrm{~m}$ grid.

\section{DISCUSSION}

\section{Definitions for proposed SUDS techniques}

The abbreviation SUDS is an acronym for Sustainable Urban Drainage System or also known as Best Management Practice (BMP) in the USA (Scholz, 2006). For the purpose of the case studies, a SUDS is defined as either an individual or a series of management structures and associated processes designed to drain surface runoff in a sustainable approach to predominantly alleviate capacities in existing conventional drainage systems (predominantly combined sewers in Glasgow) in an urban environment (SEPA, 1999; Butler and Davis, 2000; CIRIA, 2000; Scholz, 2006).

The pond proposed for the Belvidere Hospital area is a depression structure that increases the duration of the flow hydrograph with a consequent reduction in peak flow, with the depression having a minimum depth of water present at all times, and an overflow outlet to the river. The pond can be used for attenuation, detention, retention, storage, infiltration, and recreational purposes (Guo, 2001; Scholz, 2003, 2004). As the pond matures, it may become heavily vegetated, and could be classified

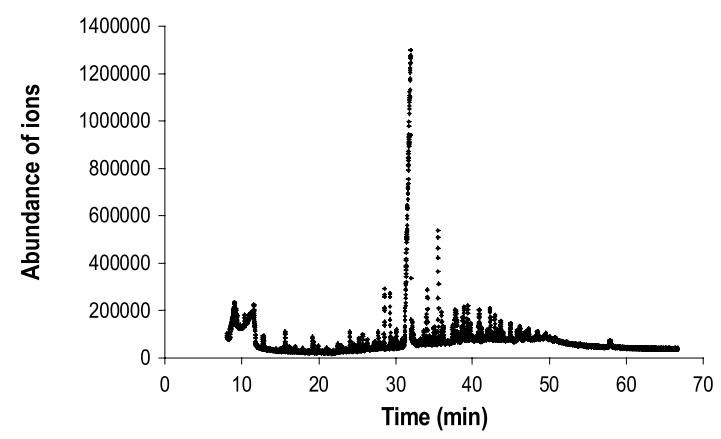

Figure 7. Belvidere Hospital area (proposed pond location): gas chromatograph findings associated with organic contamination of soil at $50 \mathrm{~cm}$ depth on 5 July 2004. as a wetland with the potential to enhance the ecological habitat (Scholz and Trepel, 2004; Scholz, 2006).

The proposed network of swales at the Belvidere Hospital comprises grass-lined conveyance structures (approximately $5 \mathrm{~m}$ in width) designed to infiltrate but predominantly to transport runoff from the site, while controlling the flow and quality of the surface water. The swales convey water to a river via a pond. The contaminated soil will have to be removed to avoid the leaching of metals into the runoff (Scholz, 2006).

The proposed infiltration trenches in the Celtic FC Stadium area are linear drains (also known as French Drains). An infiltration trench consists of a trench filled with a permeable material and with a perforated pipe at designated depth to promote infiltration of surface runoff to the ground. Some of the infiltration trenches will also convey water, if their gradient is sufficiently steep (Scholz, 2006).

Underground stormwater storage tanks have been proposed for the Celtic FC Stadium car parking areas. These subsurface structures are designed to accumulate surface runoff, and release it subsequently, as may be required to increase the flow hydrograph, if there is no risk of flooding. Moreover, the structure may contain aggregates or plastic boxes (e.g., Matrix Geo-Cell detention system promoted by Atlantis Water Management Ltd.) and can act also as a water recycler or infiltration device (Scholz, 2006).

\section{Relevant soil contamination guidance}

The soil contaminants summarized in Tables 3 to 5 should be seen in context with soil contamination guidelines (Society of the Chemical Industry, 1979; Ministry of Housing, Spatial Planning and Environment, 2000; Environment Agency, 2002). The guidelines specify thresholds for heavy metals such as chromium, copper, manganese, nickel, lead, and zinc.

Concerning chromium, the threshold for residential properties with and without plant uptake is 130 and 200 $\mathrm{mg} / \mathrm{kg}$ dry weight, respectively. In contrast, the thresh- 


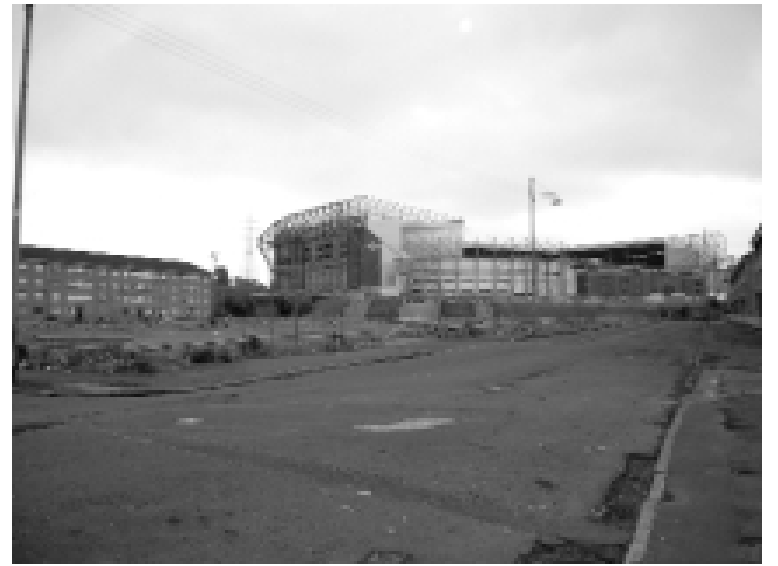

Figure 8. Celtic FC Stadium area: site photograph taken on 14 May 2004.

old for commercial and industrial land is $5,000 \mathrm{mg} / \mathrm{kg}$ dry weight (Environment Agency, 2002). In comparison, the Dutch intervention concentration is $380 \mathrm{mg} / \mathrm{kg}$ dry weight (Ministry of Housing, Spatial Planning and Environment, 2000) while the Kelly threshold (i.e., Kelly Indices Guidelines for Contaminated Soils; specifically developed for gasworks sites in London) is $200 \mathrm{mg} / \mathrm{kg}$ dry weight (Society of the Chemical Industry, 1979). However, chromium is not a major concern for both selected case study areas.

Concerning copper, the Dutch intervention concentration is $190 \mathrm{mg} / \mathrm{kg}$ dry weight (Ministry of Housing, Spatial Planning and Environment, 2000) while the Kelly threshold is $200 \mathrm{mg} / \mathrm{kg}$ dry weight (Society of the Chemical Industry, 1979). Concerning manganese, the Kelly threshold is $1,000 \mathrm{mg} / \mathrm{kg}$ dry weight (Society of the Chemical Industry, 1979). Nevertheless, neither copper nor manganese are a particular concern for both selected case study areas.

Concerning nickel, the threshold for residential properties with and without plant uptake is 50 and $75 \mathrm{mg} / \mathrm{kg}$ dry weight, respectively. In contrast, the threshold for commercial and industrial land is $5,000 \mathrm{mg} / \mathrm{kg}$ dry weight (Environment Agency, 2002). In comparison, the Dutch intervention concentration is $210 \mathrm{mg} / \mathrm{kg}$ dry weight (Ministry of Housing, Spatial Planning and Environment, 2000), while the Kelly threshold is $50 \mathrm{mg} / \mathrm{kg}$ dry weight. However, the latter concentration is correct for available nickel only (Society of the Chemical Industry, 1979). Except for the East of the Celtic FC Stadium area, nickel is not a problem for both case studies.

Concerning lead, the threshold for residential properties (with and without plant uptake) is $450 \mathrm{mg} / \mathrm{kg}$ dry weight. In contrast, the threshold for commercial and industrial land is $750 \mathrm{mg} / \mathrm{kg}$ dry weight (Environment
Agency, 2002). In comparison, the Dutch intervention concentration is $530 \mathrm{mg} / \mathrm{kg}$ dry weight (Ministry of Housing, Spatial Planning and Environment, 2000) while the Kelly threshold is $1,000 \mathrm{mg} / \mathrm{kg}$ dry weight (Society of the Chemical Industry, 1979). Lead is a major problem for both case study areas. Depending on further ground investigations, it is, however, likely that large quantities of top soil need to be removed on both sides before new residential developments can be built.

Concerning zinc, the Dutch intervention concentration is $720 \mathrm{mg} / \mathrm{kg}$ dry weight (Ministry of Housing, Spatial Planning and Environment, 2000) while the Kelly threshold is $500 \mathrm{mg} / \mathrm{kg}$ dry weight (Society of the Chemical Industry, 1979). Zinc is potentially a major problem for both case study areas. It is likely that top soil in some parts of both selected demonstration sites needs to be removed before new residential developments can be built.

\section{Cost-benefit analysis}

It has often been questioned if the reduction of pollution and runoff volume justifies the (potentially additional) costs of SUDS. Concerning both selected case studies, planning permission will only be given if the developers can demonstrate that no additional runoff will impact on the existing sewer system during storm event. It follows that either SUDS or a more traditional drainage solution in form of a detention system (e.g., large below

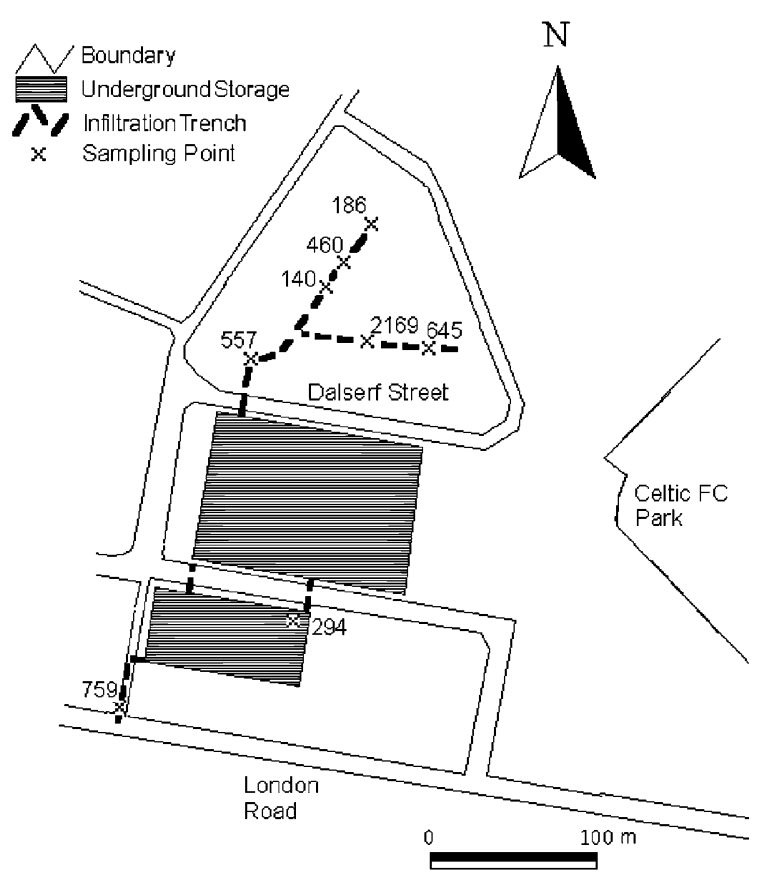

Figure 9. Celtic FC Stadium area: spatial distribution of lead (mg/kg dry weight) at $50 \mathrm{~cm}$ depth on 21 July 2004. 


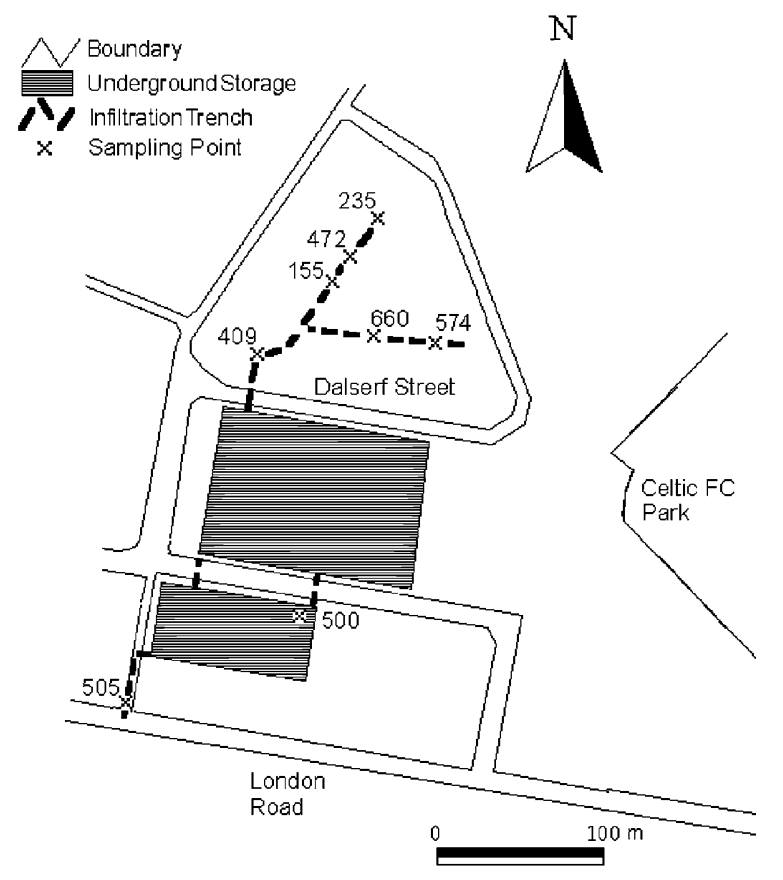

Figure 10. Celtic FC Stadium area: spatial distribution of zinc (mg/kg dry weight) at $50 \mathrm{~cm}$ depth on 21 July 2004.

ground storage tank) has to be considered during the planning phase.

Concerning the Belvidere Hospital area, the capital costs for both systems is likely to be similar (approximately $£ 700 \mathrm{k}$ ) as shown in previous studies in Scotland (Broad and Barbarito, 2004). A traditional solution would provide more space for housing while a SUDS solution has the additional benefit of enhancing the ecological value of a landscape and reduce environmental pollutants. However, unless the SUDS can be integrated into the proportion of green space that is usually reserved for recreational purposes (i.e., approximately $10 \%$ of a new site), the traditional system is likely to be marginally less expensive. On the other hand, the maintenance costs of SUDS are usually lower (approximately by $30 \%$ ) than for conventional systems (Butler and Davis, 2000; Broad and Barbarito, 2004).

Concerning the Celtic FC Stadium area, the proposed SUDS solution (i.e., predominantly underground storage) is virtually the same as a traditional subsurface detention tank. Estimated capital costs are approximately £500k. Therefore, the maintenance will also be virtually identical. Retrofitting of a detention system can easily be justified with flood prevention measures considering that this part of Glasgow is subject to frequent and regular devastating floods. The gained sewer storage space can subsequently justify the regeneration of neighboring estates where currently most flats are empty.
A detailed cost-benefit analysis comparing SUDS with traditional drainage systems or even comparing different SUDS treatment trains with each other is beyond the scope of this paper. Moreover, the planning phase has not progressed sufficiently to enable a calculation to be based on detailed information.

\section{Belvidere Hospital area design proposal}

Future building design plans for the Belvidere Hospital area are not yet finalized, as planning permission has yet to be sought by Kier Homes (former owner: National Health Trust). However, medium density residential properties are assumed to dominate a future landscape, and thus all SUDS recommendations have been made with regard to this assumption (Figs. 5 and 6).

The main entrance to the Belvidere Hospital area is located approximately in the middle of the northeast face of the area adjacent to London Road. Two large vegetated areas flank the main driveway, which runs from the main entrance in a southwesterly direction. The driveway separates two fields suitable for housing: The first field to the northwest of the main driveway is overgrown with some small trees and shrubs. The dimensions of this site are approximately $150 \times 150 \mathrm{~m}$. The second field, which is located to the southwest of the main driveway, is also overgrown but contains residual asphalted car parking and building foundations throughout. The area is approximately $150 \times 450 \mathrm{~m}$ in size. Both areas are mainly level apart from some depressions towards the southwest and south of the site (Figs. 5 and 6).

A central depression exists to the southeast of the remaining building. This area has therefore been identified as an ideal location for the implementation of a detention and attenuation pond and an associated outlet swale (or culvert) structure, and it is therefore recommended that no building construction work should be undertaken in this part of the Belvidere Hospital area. Moreover, the residual foundations in the centre of the Belvidere Hospital area appear to be at ground floor level with an existing basement level beneath in a depression. Excavation of these structures would form a suitable depression for a detention pond, which would provide a sufficient attenuation period for surface runoff.

The best engineering option recommended is to have essentially two interconnected networks of swales throughout both fields allowing suitable spacing for a medium-dense housing development. Also, it is recommended that the existing building's guttering should be redirected into a swale, which should be connected with the inlet structure of the detention pond that serves also the combined network of both swale systems (Figs. 5 and 6). 
The detention pond area should include space for decorative embankment planting, seating areas, and a footpath circling the pond and woodland to create a high amenity value by providing interesting landscaping features to the local community (Figs. 4-6).

From this detention pond a further cascading swale, acting as a combined overflow and outlet structure should flow down the embankment through the existing glade of mature tress to the public river walkway (Figs. 5 and 6). It is recognized that a swale may be difficult to construct due to the established vegetation, and therefore, a cascade of small ponds (interconnected with a culvert) or an open channel (lined with decorative brick) or even a subsurface pipe may be more suitable for some stretches pending on an outstanding ecological habitat assessment. A suitable provision should be made to allow the overflow to flow under or across the walkway by means of guttering into the River Clyde.

Transport structures such as feeder roads and car parks should be constructed from permeable or pervious pavement. A short culvert below the main driveway (connecting London Road with the former hospital building), which is expected to be retained, from the swale network in the north to the detention pond in the center of the area should be considered (Figs. 5 and 6).

Contaminants such as manganese, lead (Fig. 5) and to a lesser extend zinc (Fig. 6) are present in high concentrations in the soil (Tables 3-5). The soil in the center southwest of the area is heavily contaminated with lead and zinc and would require removal. However, lead in particular is very difficult to dissolve in water, and would not cause a problem for the outflow concentration of most SUDS structures (Scholz et al., 2002).

The concentration of organic compounds found was low (estimated to be less than $1 \mathrm{mg} / \mathrm{kg}$ ). Compounds found included polycyclic aromatic hydrocarbons (PAH). For example, pyrene, fluoranthene, chrysene, benz(a)anthracene, benzo(k)fluoranthene, benz(a)pyrene, and benzo(g,h,i)perylene were found at very low concentrations at Belvidere Hospital (proposed pond location). Other compounds found included aliphatic hydrocarbons such as tetracosane, eicosane, heptadecane, heptacosane, and nonadecane which are commonly constituents of diesel-type fuels. Phenol derivatives and carbolic acid related compounds were also found. These types of compounds were often used as cleaning agents and disinfectants in hospitals and schools (Fig. 7).

\section{Celtic FC stadium area design proposal}

The areas surrounding the Celtic Park stadium (Fig. 8) are currently under development and regeneration. Celtic FC was granted planning consent in 1994 for the rede- velopment of the stadium to from an all-seated stadium with a capacity for 60,000 spectators. As part of this planning application, the club was required to provide 377 car-parking spaces within the curtilage of the stadium. This has been achieved to the satisfaction of Glasgow City Council.

In 1998, the club was granted planning consent for the formation of a temporary coach park on the site of a former bakery in the Camlachie to the West of the stadium. This consent allowed for the parking of 171 coaches, and was granted for a period of 3 years until June 2001. Renewal of this consent was granted in July 2001, for a further period of 3 years. This facility is used for coaches of home supporters. The catchment area excluding the stadium is about $58,500 \mathrm{~m}^{2}$.

Considering the current state of the Celtic FC car park and its heavy use during match days, this area would be ideal for an integrated underground storage system underneath the present car park. The suggested area in the West for the integration of underground storage facilities is the site surrounded by Dalserf Street in the north and Barrowfield Street in the south. The storage area would be approximately $14,600 \mathrm{~m}^{2}$. A further but smaller underground storage area of $4,900 \mathrm{~m}^{2}$ could be located in the southeast of the main storage tank just south of Barrowfield Street (Figs. 9 and 10).

According to a recent site investigation and the current characteristics of the area in the north, the construction of a simple infiltration trench network with two branches seems to be feasible. The branches of the infiltration trench network should be located in the north and northeast, respectively. The land in the north is associated with the highest ground level in the study area. The infiltration trench network will transfer the water from the roofs and paved surfaces to the major underground storage through an inlet in the northwest of the main storage tank (Figs. 9 and 10).

Infiltration trenches or culverts should connect the two storage tanks and transfer the runoff to the smaller storage tank and when required to the sewer system located on London Road. The overflow of the storage tank system is located in the southwest of the study area (Figs. 9 and 10).

Considering the current state of the Celtic FC car park in the west, renovation work is likely to be required within a couple of years. The implementation of the recommended SUDS would therefore be easily approachable.

The area is contaminated with lead (Fig. 9) and zinc (Fig. 10) that might be linked to pollution from cars (Tables 3-5). The soil requires removal, if used by residents in the future. However, particularly lead is very difficult to dissolve in water (Scholz et al., 2002), and is unlikely 
to cause a problem for the outflow concentration of underground SUDS structures if $\mathrm{pH}$ levels are high and conductivity values low (Scholz and Trepel, 2004; Scholz, 2006).

The overall concentration of organic compounds found was low (estimated to be less than $0.5 \mathrm{mg} / \mathrm{kg}$ ). Compounds found included PAH. For example, pyrene, fluoranthene, chrysene, benz(a)anthracene, benzo(k)fluoranthene, benz(a)pyrene, and $\operatorname{benzo}(\mathrm{g}, \mathrm{h}, \mathrm{i})$ perylene were found at very low levels in the Celtic FC Stadium area (at the proposed network of swales). Other compounds found included aliphatic hydrocarbons such as tetracosane, eicosane, heptadecane, heptacosane, and nonadecane, which are commonly constituents of diesel-type fuels.

\section{SUMMARY AND CONCLUSIONS}

A survey of 57 sites within 46 areas of Glasgow shows that it is feasible to implement different SUDS techniques throughout Glasgow. The likely contribution of future SUDS to the overall catchment dynamic of representative demonstration areas has been assessed. The preliminary designs will help to understand the challenges of holistic catchment management, diffuse pollution, and the linking scales in catchment management. The implementation of SUDS will help to relief the local sewer system, and subsequently allows for more regeneration activities to take place.

Characteristics that determine the suitability of a site for the implementation of SUDS have been identified. Representative areas and sites that are suitable for different representative SUDS techniques have been identified qualitatively and quantitatively. A SUDS decision support key and matrix that are adaptable to different cities have been proposed. The matrix can be used as part of a decision support model in the future.

Seven entirely different SUDS demonstration areas that are representative for both different sustainable drainage techniques and different types of areas available for development, regeneration, and retrofitting of SUDS within Glasgow have been identified. Design and management guidelines for demonstration sites that should be constructed to inform and educate the public, developers, and politicians have been proposed. Underground storage tanks and ponds linked with swales and infiltration trenches have been identified as the most useful sustainable drainage techniques for large sites within Glasgow.

Concerning the case studies, the proposed drainage system for the Belvidere Hospital area is dominated by a network of swales draining into a large attenuation and detention pond. The runoff will ultimately drain from the pond into a nearby river. In comparison, the drainage of the Celtic FC Stadium area is dominated by two large underground detention tanks beneath car parks. The runoff, after a considerable lag period, will ultimately drain into the sewer after the risk of flooding has gone down.

Furthermore, a brief cost-benefit analysis has shown that the capital costs for the proposed SUDS solutions are likely to be similar to the costs for a comparable traditional drainage system. However, a SUDS solution would be preferable, if it could be integrated into the area reserved for green space.

The soils for both selected case studies are contaminated predominantly with lead and zinc. Moreover, hot spots of nickel contamination were detected in the east of the Celtic FC Stadium area. In comparison, organic contamination was insignificant.

The application of the SUDS decision support matrix has identified that unlined SUDS structures such as swales can only be implemented if the risk of runoff being contaminated by metal leaching is eliminated. Large quantities of top soil therefore require removal before construction work on residential properties can commence to avoid environmental and water pollution as well as potential health problems for the residents.

\section{ACKNOWLEDGMENTS}

The authors wish to thank the planners in Glasgow (B. Aaen and S. Gillon) for their advice and guidance. Technical support was provided by R. Morgan, P. Anderson, T. Devillers, F. Maratray, A. Picher, A.S. Khan, and J.P. Andrzejczak. The research was directly sponsored by The Royal Academy of Engineering (Global Research Award; awarded to M. Scholz in April 2004), Glasgow City Council, and British Council (IAESTE UK). The project received in kind contributions from the European Union, The University of Edinburgh, Ecole des Mines de Nantes, Ecole des Mines d'Albi, Ecole Nationale Superieure D'Ingenieurs de Limoges, and Technical University of Denmark.

\section{REFERENCES}

ALLEN, S.E. (1974). Chemical Analysis of Ecological Materials, 1st ed. Oxford, UK: Blackwell Scientific Publications.

AMERICAN PUBLIC HEALTH ASSOCIATION. (1995). Standard Methods for the Examination of Water and Wastewater, 19th ed. Washington DC: Author.

BRITISH STANDARD INSTITUTE. (1999a). Soil QualityPart 3: Chemical Methods-Section 3.5: Pre-treatment of Samples for Physico-chemical Analysis. BS 7755-3.5:1995 and ISO 11464:1994. 
BRITISH STANDARD INSTITUTE. (1999b). Soil QualityPart 5: Physical Methods-Section 5.4: Determination of Particle Size Distribution in Mineral Soil Material—Method by Sieving and Sedimentation. BS 7755-5.4:1998 and ISO 11277:1998.

BRITISH STANDARD INSTITUTE. (2002). Soil QualityFormat for Recording Soil and Site Information. BS ISO 15903:2002.

BROAD, W., and BARBARITO, B. (2004). Examination of site selection methodologies for the retrofit of SUDS. In N.J. Horan, Ed., Proceedings of the Second National Conference of The Chartered Institution of Water and Environmental Management, Wakefield, England, p. 319.

BUTLER, D., and DAVIS, J.W. (2000). Urban Drainage. London, UK: Spon.

BUTLER, D., and PARKINSON, J. (1997). Towards sustainable urban drainage. Water Sci. Technol., 35, 53.

CIRIA. (2000). Sustainable Urban Drainage Systems: Design Manual for Scotland and Northern Ireland. Construction Industry Research and Information Association (CIRIA), Report C521. Trowbridge, UK: Cromwell Press.

COUNCIL OF EUROPEAN COMMUNITIES. (2000). Directive of 23 October 2000 establishing a framework for community action in the field of water policy (2000/60/EC). Official Journal, L327, 0001.

D'ARCY, B., and FROST, A. (2001). The role of best management practices in alleviating water quality problems associated with diffuse pollution. Sci. Total Environ. 265, 359.

DEFRA. (2000). Second Consultation Paper on the Implementation of the EC Water Framework Directive (2000/60/EC). London, UK: Department for Environment, Food and Rural Affairs (DEFRA).

ENVIRONMENT AGENCY. (2002). Soil Guideline Values for Lead, Chromium, Nickel and other contaminants (individual papers). Bristol, UK: Department for Environment, Food and Rural Affairs.

FOWLER, J., and COHEN, L. (1998). Practical Statistics for Field Biology. West Sussex, UK: John Wiley \& Sons.

GLASGOW CITY COUNCIL. (1980). Report on Site Investigation at Janefield Street. Site Report No E186 (1). Glasgow, UK: Department of Architecture and Related Services.

GLASGOW CITY COUNCIL. (1995). Preliminary Desk Study Report of Ground Conditions at Dalriada Street/Janefield
Street, Parkhead. Project No PATAD023. Glasgow, UK: Department of Architecture and Related Services.

GUO, Y. (2001). Hydrologic design of urban flood control detention ponds. ASCE J Hydrol Eng. 6, 472.

JEFFERIES, C., AITKEN, A., MCLEAN, N., MACDONALD, K., and MCKISSOCK, G. (1999). Assessing the performance of urban BMPs in Scotland. Water Sci. Technol. 39, 123.

KOSSON, D.S., VAN DER SLOOT, H.A., SANCHEZ, F., and GARRABRANTS A.C. (2002). An integrated framework for evaluating leaching in waste management and utilization of secondary materials. Environ. Eng. Sci. 19, 159.

MCKISSOCK, G., JEFFERIES, C., and D'ARCY, B.J. (1999). An assessment of drainage best management practices in Scotland. J. Ch. Instram. Water \& Environ. Manage. 13, 47.

MINISTRY OF HOUSING, SPATIAL PLANNING AND ENVIRONMENT. (2000). Circular on Target Values and Intervention Values for Soil Remediation. Reference No. DBO/1999226863. The Hague, The Netherlands: Ministry of Housing, Spatial Planning and Environment.

SCHOLZ, M. (2003). Sustainable operation of a combined flood-attenuation wetland and dry pond system. J. Ch. Instram. Water Environ. Manage. 17, 171.

SCHOLZ, M. (2004). Treatment of gully pot effluent containing nickel and copper with constructed wetlands in a cold climate. J. Chem. Technol. Biotechnol. 79, 153.

SCHOLZ, M. (2006). Wetland Systems to Control Urban Runoff, 1st ed. Amsterdam, The Netherlands: Elsevier.

SCHOLZ, M., and TREPEL, M. (2004). Water quality characteristics of vegetated groundwater-fed open ditches in a riparian peatland. Sci. Total Environ. 332, 109.

SCHOLZ, M., HÖHN, P., and MINALL, R. (2002). Mature experimental constructed wetlands treating urban water receiving high metal loads. Biotechnol. Prog. 18, 1257.

SEPA. (1999). Protecting the Quality of our Environment-Sustainable Urban Drainage: An Introduction. London, UK: Stationary Office.

SOCIETY OF THE CHEMICAL INDUSTRY. (1979). Site investigation and materials problems. In Society of the Chemical Industry, Proceedings of the Conference on Reclamation of Contaminated Land, Eastborne, UK. 